\title{
Proving the suitability of magnetoelectric stimuli for tissue engineering applications
}

\author{
C. Ribeiro ${ }^{a}$, V. Correia ${ }^{\mathrm{a}, \mathrm{b}}$, P. Martins ${ }^{\mathrm{a}}$, F.M. Gama ${ }^{\mathrm{c}}$, S. Lanceros-Mendez ${ }^{\mathrm{a}, \mathrm{d}, *}$ \\ a Centro/Departamento de Física, Universidade do Minho, Campus de Gualtar, 4710-057 Braga, Portugal \\ b Algoritmi Research Centre, Universidade do Minho, Campus de Azurém, 4800-058 Guimarães, Portugal \\ ' IBB e Institute for Biotechnology and Bioengineering, Centre of Biological Engineering, Universidade do Minho, Campus de Gualtar, 4710-057 Braga, \\ Portugal \\ ${ }^{\mathrm{d}}$ BCMaterials, Parque Científico y Tecnológico de Bizkaia, 48160, Derio, Spain
}

\section{A R T I C L E I N F O}

\section{Article history:}

Received 27 October 2015

Received in revised form

28 December 2015

Accepted 29 December 2015

Available online 4 January 2016

\section{Keywords:}

Bone tissue engineering

Cell proliferation

Magnetic stimulus

Magnetoelectric

\begin{abstract}
A B S T R A C T
A novel approach for tissue engineering applications based on the use of magnetoelectric materials is presented. This work proves that magnetoelectric Terfenol-D/poly(vinylidene fluoride-co-trifluoroethylene) composites are able to provide mechanical and electrical stimuli to MC3T3-E1 pre-osteoblast cells and that those stimuli can be remotely triggered by an applied magnetic field. Cell proliferation is enhanced up to $\approx 25 \%$ when cells are cultured under mechanical (up to $110 \mathrm{ppm}$ ) and electrical stimulation (up to $0.115 \mathrm{mV}$ ), showing that magnetoelectric cell stimulation is a novel and suitable approach for tissue engineering allowing magnetic, mechanical and electrical stimuli.
\end{abstract}

(C) 2015 Elsevier B.V. All rights reserved.

\section{Introduction}

Tissue engineering (TE) techniques aim to mimic the physicochemical and bioactive characteristics of natural cellular matrices, both for therapeutic applications and fundamental biological studies $[1,2]$, the replacement and/or regeneration of lost/damaged tissues or organs representing one of the main challenges [3-5]. Cells, scaffolds and growth factors are the three main components of TE strategies [6].

Biomaterials interface plays an important role on cell adhesion, proliferation and differentiation. Further, biomaterials can be tailored not only to be passively tolerated by the organism, but also to provide the appropriate environment to assist specific cell responses [7].

In this way, diverse strategies are being implemented for the development of novel scaffolds to support restoring native tissue functionalities, including bone, muscle and nerve $[1,8]$. In particular, an increasing number of patients suffer from bone related diseases [9], bone TE becoming increasingly relevant and with strong socio-economic impact [10,11].

\footnotetext{
* Corresponding author at: Center/Department of Physics, University of Minho, Campus de Gualtar, Braga 4710-057, Portugal. Fax: +351 253604061

E-mail address: lanceros@fisica.uminho.pt (S. Lanceros-Mendez).
}

Therefore, the development of new materials for bone TE is under intense investigation [9,11]. Bone TE strategies are typically based on scaffolds as passive cell supports, including porous materials [12], 3D architectures [13] and fibers [14] as well as materials reinforced with hydroxyapatite [15], but a suitable approach has not been achieved so far.

Most of those strategies do not take into account one of the relevant properties of natural bone tissue, which is its piezoelectricity [16]. This means that when a mechanical solicitation (stress) is applied to the bone, it produces a voltage variation that strongly influences characteristic and performance of bone tissue all along its developing and functional time. In this way, the use of electrically active biomaterials is an attractive and probably necessary approach for bone TE. The potential of such electroactive smart materials in this field exploited so far mainly piezoelectric poly(vinylidene fluoride) (PVDF) or copolymers such as poly(vinylidene fluoride-co-trifluoroethylene) (PVDF-TrFE), the piezoelectric polymers with the largest response [17-19]. Indeed, the influence of surface polarity of PVDF films on bone cell response shows that polymer surface charges promote cell adhesion, proliferation and differentiation $[18,20]$. Further, under dynamic mechanical conditions, piezoelectric substrates improve osteoblast growth and differentiation $[17,18]$. This biomimetic approach is particularly relevant as bone, like other tissues, is physiologically subjected to mechano-electrical solicitations related to walking, 
jumping and running [16]. However, in some cases, the patient is immobilized due to serious health condition, and as a result the natural mechanical stimulus does not occur [21], thus decreasing the effectiveness of piezoelectric biomaterials. Such limitation claims for the development of new materials able to remotely mechanical and/or electrically stimulate tissues from outside of the human body $[22,23]$ and/or for specific cell cultures in bioreactors.

Magnetoelectric (ME) composite materials provide such an innovative tool, allowing the use of an external magnetic field to remotely control tissue stimulation [23], without the need of patient movement. Those composites consist on the combination of magnetostrictive and piezoelectric materials, the ME effect being the result of a product property [24]. The mechanical deformation induced by a magnetic field due to the magnetostriction of one of the components, results in a electrical polarization variation due to the piezoelectric effect of the other phase, allowing large ME effects at room temperature $[25,26]$. Thus, the magnetic actuation ability of the ME composite allows the mechanical and electrical stimulus of neighboring cells [27]. As bone TE requires biomaterials with flexibility, lightweight, versatility and biocompatibility [8,28], polymer-based ME materials can be taken to advantage [27].

Two main types of polymer-based ME composites can be found in the literature: laminated composites and particulated micro and nanocomposites [27]. Despite the lower $\mathrm{ME}$ response of $\mathrm{P}(\mathrm{VDF}-\mathrm{TrFE}) / \mathrm{CoFe}_{2} \mathrm{O}_{4}$ nanocomposites [29] $\left(42 \mathrm{mV} \mathrm{cm}^{-1} \mathrm{Oe}^{-1}\right)$-four orders of magnitude lower than the one $\left(383 \mathrm{~V} \mathrm{~cm}^{-1} \mathrm{Oe}^{-1}\right)$ reported for $\mathrm{P}(\mathrm{VDF}-\mathrm{TrFE}) /$ Metglas 2605SA1 laminates [30] - its higher flexibility, simple fabrication, easy shaping, the possibilities of miniaturization and the absence of degradation at the piezoelectric/magnetostrictive interface are obvious advantages $[27,30,31]$. Further, particulate composites allow the development of geometries suitable for tissue engineering, including spheres [25] and fiber mats [32], allowing also cell culture and specific TE approaches. Finally, the incorporation of magnetic nanoparticles into scaffolds acting synergistically with the magnetic field in vivo will improve cellular proliferation and differentiation, and promote an enhancement of tissue integration into the scaffold, a crucial step towards the clinical applications of the composites [33,34].

Thus, this work demonstrates the suitability of polymer-based ME composites for tissue engineering, providing thus a novel platform for innovative tissue engineering strategies based on magnetic, electrical and mechanical stimuli. In particular, the influence of the external magnetic field stimulation in MC3T3-E1 pre-osteoblast cells proliferation [35] on a Terfenol-D/P(VDF-TrFE) ME composite scaffold is reported. Terfenol-D was chosen due to its biocompatibility and high magnetostrictive coefficient [36,37] and $\mathrm{P}(\mathrm{VDF}-\mathrm{TrFE})$ due to its proven potential for bone, muscle, and neuronal tissue engineering applications, biocompatibility, high piezoelectric coefficient and crystallization on the piezoelectric phase from solvent casted samples [38,39].

\section{Experimental}

\subsection{Materials}

All the chemicals and particles were used as received from the suppliers: Terfenol-D (TD) $\approx 1 \mu \mathrm{m}$ of random particles from Etrema Products, $\mathrm{N}, \mathrm{N}$-dimethylformamide (DMF, pure grade) from Fluka and poly(vinylidene fluoride-co-trifluoroethylene), P(VDFTrFE), from Solvay Solexis.
Table 1

Scaffolds used for cell culture.

\begin{tabular}{llcc}
\hline \multicolumn{2}{c}{ Denomination } & Samples & \multicolumn{2}{c}{ Polarization } & Stimulus & Film response \\
\hline A & PVDF-TrFE non poled & $\times$ & Magnetic None \\
B & PVDF-TrFE/TD non poled & $\times$ & Mechanical \\
C & PVDF-TrFE/TD “poled +" & $\sqrt{ }$ & Electrical \\
\hline
\end{tabular}

\subsection{Films preparation}

Films were prepared based on the method presented in $[40,41]$ for similar polymer-based composite compositions. In short, Terfenol-D particles were added to DMF and placed in an ultrasound bath for $8 \mathrm{~h}$ in order to ensure proper dispersion of the particles. $\mathrm{P}(\mathrm{VDF}-\mathrm{TrFE})$ polymer was then added and mixed during $2 \mathrm{~h}$ with the help of a mechanical Teflon stirrer, in an ultrasound bath to avoid magnetic particle agglomeration during the mixing process. After that, the solution was spread in a clean glass substrate and solvent evaporation took place inside an oven at $210^{\circ} \mathrm{C}$ for $10 \mathrm{~min}$. Polymer crystallization was achieved by cooling down films to room temperature. At the end of this process, TD particles were inside the polymer matrix and $\approx 50 \mu \mathrm{m}$ thick films were peeled from the glass substrate.

$\mathrm{TD} / \mathrm{P}(\mathrm{VDF}-\mathrm{TrFE})$ composites with 40 weight percentage ( $40 \mathrm{wt. \%}$ ) of TD particles content were produced, since preliminary tests demonstrated that TD such composition provides a good ME response with suitable mechanical properties (e.g., flexibility) [29].

Film poling was achieved using an optimized procedure, consisting on a corona treatment at $10 \mathrm{kV}$ during $120 \mathrm{~min}$ at $120^{\circ} \mathrm{C}$, in a home-made chamber, and cooling down to room temperature under applied electric field. The piezoelectric response $\left(d_{33}\right)$ of the samples was analyzed with a wide range $\mathrm{d}_{33}$-meter (model 8000 , APC Int., Ltd.).

For in vitro assays, circular films were cut with $13 \mathrm{~mm}$ of diameter. Non-poled films (with and without magnetic particles) were used to study the effect of the magnetic field and magnetostriction in the cell culture and poled films to study the influence of the ME stimulus in cell behavior (Table 1 ).

For sterilization proposes, the films were exposed to ultraviolet light (UV) for $1 \mathrm{~h}$ on each side. After that, samples were placed in standard 24-well cell culture plates and washed 5 times ( 5 min each time) with a phosphate buffer saline (PBS) $1 \times$ solution.

\subsection{ME characterization}

In order to obtain the out-of-plane ME coefficient $\alpha_{33}$, a DC and AC magnetic field were applied along the direction of the electric polarization of the composites, i.e., perpendicular to the surface.

The AC driving magnetic field of 1 Oe amplitude at $\approx 10 \mathrm{kHz}$ (resonance frequency of the composite) was provided by a pair of Helmholtz coils and the DC field with a maximum value of $0.5 \mathrm{~T}$ was applied by an electromagnet.

The resonance frequency $\left(f_{\mathrm{r}}\right)$ of the composites was determined by Eq. (1):

$$
f_{\mathrm{r}}=\frac{n}{2 l} \sqrt{\frac{E_{\mathrm{Y}}}{\rho}}
$$

where $n, E_{\mathrm{Y}}$ and $\rho$ are the harmonic mode order, in-plane Young's modulus and density of the composites, respectively.

The induced ME voltage was measured with a Standford Research Lock-in amplifier (SR530). 

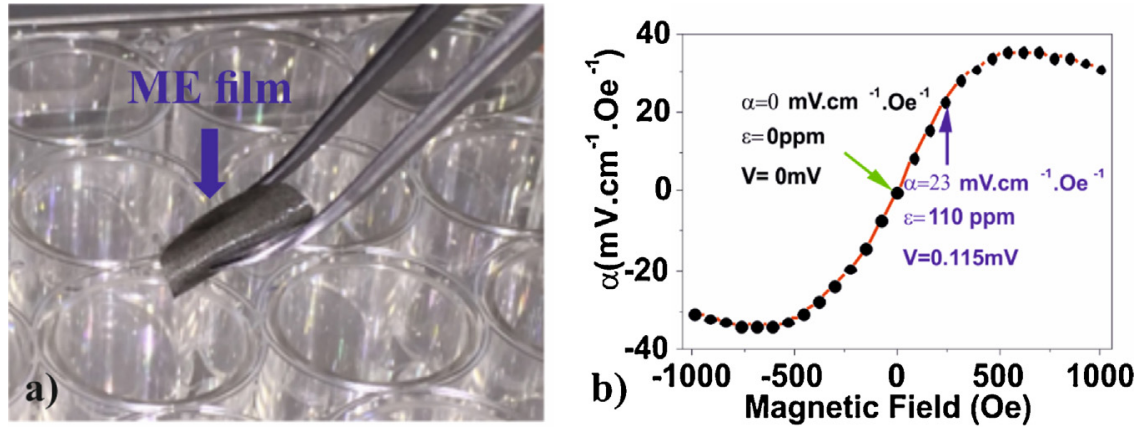

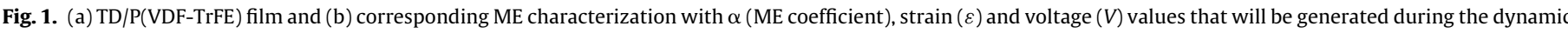
cell culture.

Based on Eqs. (2) e (3), it is possible to determine the strain $(\lambda)$ produced by the TD particles within the polymer matrix that is transmitted to the MC3T3-E1 pre-osteoblast cells [41].

$\left(\frac{d S}{d \mathrm{H}}\right)=\frac{\alpha}{m_{V} \times\left(1-m_{V}\right) \times\left(d_{33} / \varepsilon_{0} \times \varepsilon \times E_{\mathrm{Y}} \times l \times w / t\right) \text { piezoelectric }}$

where $m_{V}, \varepsilon_{0}, \varepsilon, E_{Y}, l, w$ and $t$ are the volume fraction of the TD particles, the vacuum permittivity, the relative permittivity, the Young's modulus, the length, the width and the thickness of the composite, respectively.

$\lambda=\left(\frac{d S}{d \mathrm{H}}\right) \times B_{\mathrm{S}}$

where $B_{\mathrm{S}}$ is the maximum magnetic field generated by the bioreactor.

\subsection{Cell culture}

MC3T3-E1 pre-osteoblast cells (Riken bank) were grown using in Dulbecco's modified Eagle's medium (DMEM, Gibco) containing $1 \mathrm{~g} \mathrm{~L}^{-1}$ glucose, 10\% Fetal Bovine Serum (FBS, Biochrom) and 1\% penicillin/streptomycin (P/S, Biochrom) at $37^{\circ} \mathrm{C}$ in $95 \%$ humidified air containing $5 \% \mathrm{CO}_{2}$ incubator.

For all cell culture assays, cells were seeded on each well $\left(5 \times 10^{4}\right.$ cells $\mathrm{mL}^{-1}$ ) and incubated at the above mentioned conditions for $24 \mathrm{~h}$. After this incubation time, one plate was maintained at the same conditions (static culture - cell culture without any stimulation) and the other was transferred onto a home-made bioreactor system (dynamic culture - cell culture under magnetic stimulation) for up to $48 \mathrm{~h}$ with the following cycle: an active time of $16 \mathrm{~h}$ under magnetic stimulus (divided into $10 \mathrm{~min}$ of active time and $20 \mathrm{~min}$ of repose time) followed by a non-active time of $8 \mathrm{~h}$ (no magnetic stimulation). These conditions were selected in order to mimic the human body mechanical stimulations ( $16 \mathrm{~h}$ of activity and $8 \mathrm{~h}$ resting time $[42,43])$. The dynamic culture was performed under magnetic stimulation at a frequency of $0.3 \mathrm{~Hz}$. The $20 \mathrm{~mm}$ displacement of permanent magnets below the culture wells allowed the variation of the magnetic field from a maximum value of 230 Oe-0 Oe within the culture wells, leading to ME voltages up to $0.115 \mathrm{mV}$. In each study, 2-3 replicates were used per studied condition.

\subsection{Cell viability assessment}

Cell metabolic viability was carried out by performing 3-(4,5-dimethylthiazol-2-yl)-5-(3-carboxymethoxyphenyl)-2(4-sulfophenyl)-2H-tetrazolium (MTS, Promega) assay. This is a cell viability assay based on the bioreduction of the substrate to a brown formazan product by NADPH or NADP produced by mitochondrial enzymes, which are active in living cells.

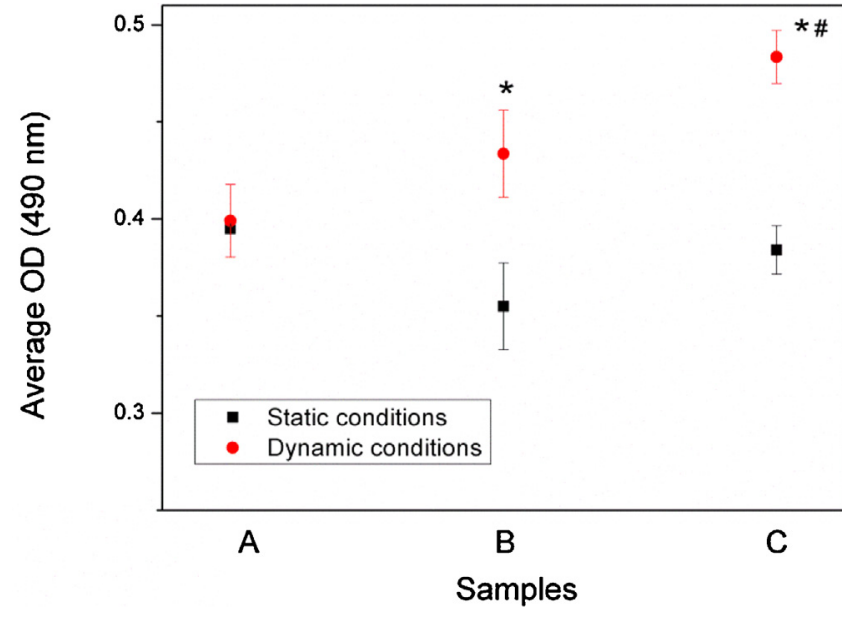

Fig. 2. MTS results from MC3T3-E1 osteoblast proliferation on the different films (A non-poled PVDF-TrFE samples, B, non-poled TD/PVDF-TrFE composites and C, poled TD/PVDF-TrFE composites) under static and dynamic conditions up to $72 \mathrm{~h}$. Values shown as mean \pm SEM (Standard error of mean). ${ }^{*} P<0.05$ vs. Sample A under static conditions; ${ }^{\#} P<0.05$ vs. Sample B under dynamic conditions.

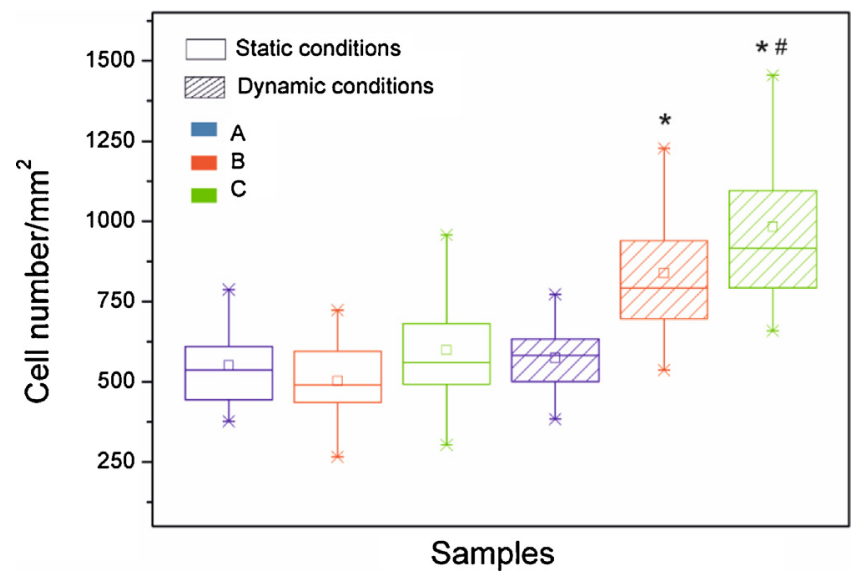

Fig. 3. Cell density (cell $\mathrm{mm}^{-2}$ ) of the different samples $(A-C)$ under static $(\square$ ) and dynamic conditions ( conditions; ${ }^{\#} P<0.05$ vs. Sample B under dynamic conditions.

For this assay, the samples were transferred to a new 24-well plate, MTS solution (in a 1:5 ratio) was added to each well and the plate was placed in a $5 \% \mathrm{CO}_{2}$ incubator at $37^{\circ} \mathrm{C}$. After $2 \mathrm{~h}$ of incubation, $100 \mu \mathrm{L}$ of each well was transferred to a 96 -well plate $(n=3)$ and the optical density (OD) of each well was measured at $490 \mathrm{~nm}$ using a spectrophotometric plate reader (Biotech Synergy HT). Triplicate measurements were performed on each sample. 
Static conditions
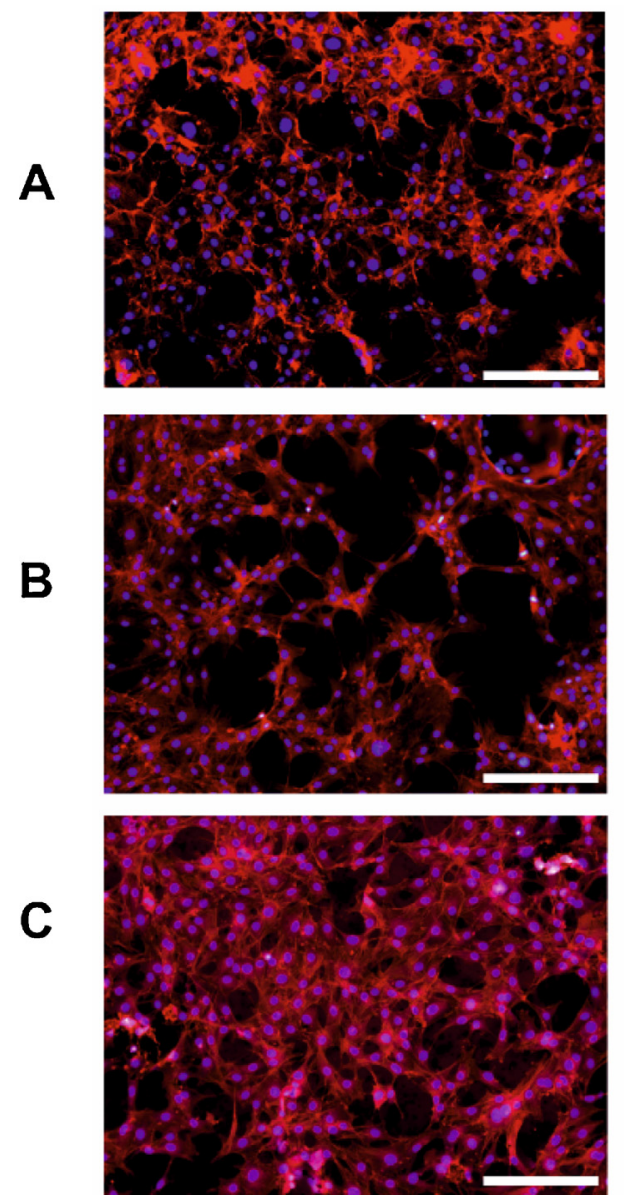

\section{Dynamic conditions}
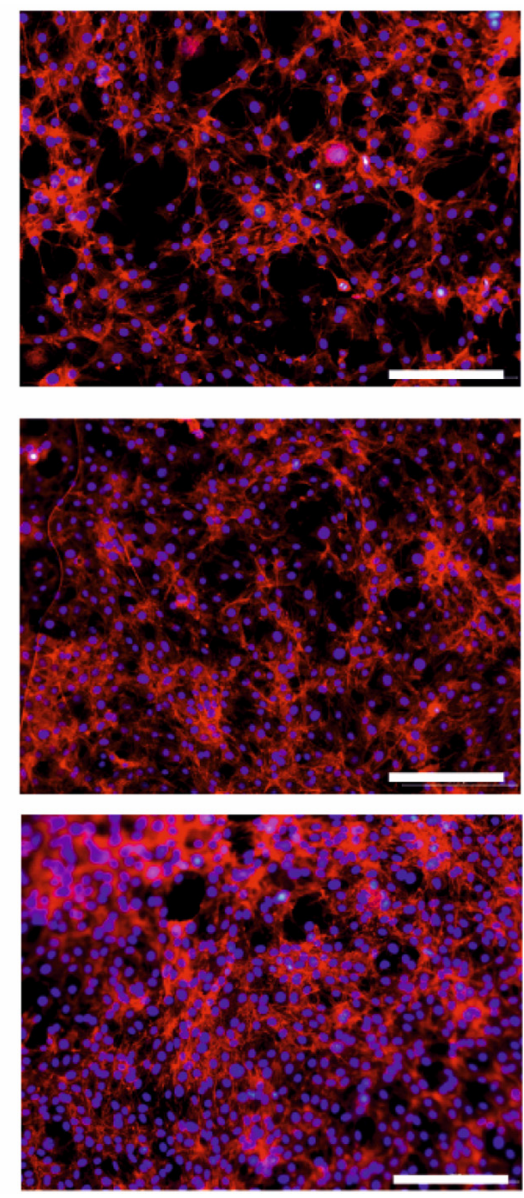

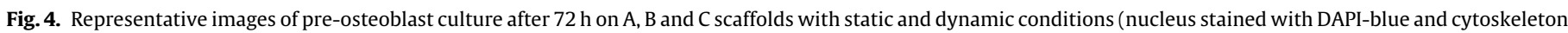
stained with TRITC-red). Scale bar $=200 \mu \mathrm{m}$. (For interpretation of the references to colour in this figure legend, the reader is referred to the web version of this article).

\subsection{Cell morphology and cell number}

The samples collected from cell culture were transferred for a new 24-well plate, washed with PBS $1 \mathrm{x}$ and the cells fixed with $4 \%$ formaldehyde (Panreac) for $10 \mathrm{~min}$ at $37^{\circ} \mathrm{C}$ in a $5 \% \mathrm{CO}_{2}$ incubator.

For cell number quantification, after fixation, all samples were washed with PBS $1 \mathrm{x}$ and stained for $10 \mathrm{~min}$ with $1 \mu \mathrm{g} \mathrm{mL}^{-1}$ of a 4,6diamidino-2-phenylindole (DAPI, Sigma) solution. After that, the samples were washed with PBS $1 \mathrm{x}$ and observed in a fluorescence microscopy (Olympus BX51 Microscope). Twenty representative fields of each well were selected in a blinded and systematic procedure using $10 \times$ magnification. For cell counting, the ImageJ software was used. Finally, cell number per $\mathrm{mm}^{2}$ were calculated.

For cell morphology, after fixation, samples were washed with PBS $1 \mathrm{x}$ three times and incubated in $0.1 \mu \mathrm{g} \mathrm{mL}^{-1}$ of red phalloidin (Sigma) solution for $45 \mathrm{~min}$ at room temperature. Finally, the samples were again washed with PBS $1 \mathrm{x}$ and incubated in $1 \mu \mathrm{g} \mathrm{mL} L^{-1}$ DAPI solution for $10 \mathrm{~min}$. Cells were washed again with PBS $1 \mathrm{x}$ and then visualized in a fluorescence microscopy.

\subsection{Statistical analysis}

All quantitative data were analyzed using GraphPad Prism (v6.00). For each data set, each condition was compared using oneway analysis of variance (ANOVA) statistical evaluation followed by Tukey's test. Differences were considered to be significant when $\mathrm{P}<$ 0.05 . The data of cell density are displayed in boxplots, the boxplots containing the following descriptive statistics: median (horizontal line), mean (square), interquartile range (box) and whiskers (outlier).

\section{Results}

It has been established that mechanical forces influence osteoblast activity $[44,45]$. Beyond the mechanical stimulus, it has been also proven that charged surfaces and piezoelectric materials enhance bone tissue regeneration $[17,46]$. In view of these facts, three different samples were used to prove the suitability of the ME effect for tissue engineering applications: A - non-poled polymer
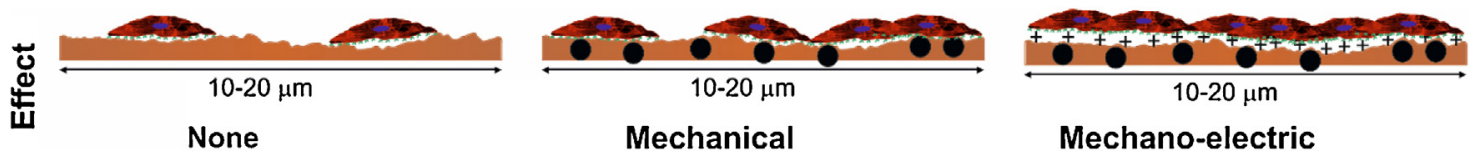

Fig. 5. Representative images of cell proliferation to each distinct scaffold. 
samples without magnetostrictive particles, acting as passive supports for cell culture (it is to notice here that poled samples without magnetic fillers will not have any reaction to the magnetic field either, showing therefore the same response that the non-poled ones under dynamic conditions); B - non-poled polymeric samples with magnetostrictive particles, with can apply mechanical stimulation to the cells when subjected to a varying magnetic field, due to the magnetostrictive effect; and C - poled polymer samples with magnetostrictive particles, which together with the mechanical stimulation, will induce a varying electrical surface charge due to the piezoelectric effect, as defined by the ME coupling.

It is important to notice at this point that the effect of sample poling on protein adsorption and cell behavior has been previously addressed in [46] and [20], respectively. Sample poling leads to an overall net surface charge influencing protein adsorption and cell response, as well as improved piezoelectric response under mechanical stimuli $[17,18]$. In the present investigation, as a magnetic stimulus is used to trigger the mechanical and the piezoelectric response of the samples and once PVDF-TrFE poled samples do not react to the magnetic stimulus, non-poled PVDF-TrFE is used as negative control. As both poled and non-poled samples do not react to the applied magnetic field, the differences among them would be the same as reported in $[20,46]$. There variations are not relevant to the present investigation in which the effect of magnetostrictive and magnetoelectric effects are considered. With poled PVDF-TrFE samples as negative control, no differences will exist between static and dynamic magnetic conditions either, but we could have a higher number of cells in the poled samples than in the non-poled ones, as previously reported [46,20].

Fig. 1 shows an image of the TD/P(VDF-TrFE) ME composite film and its ME characterization.

Fig. 1a shows the flexibility and easy shaping of the TD/P(VDFTrFE) film. The ME response of the TD/P(VDF-TrFE) composite studied between -1000 and $1000 \mathrm{Oe}$ is shown in Fig. 1b. The ME coefficient $(\alpha)$, that correlates the voltage generated across the material $(\Delta V)$ with the thickness $(\mathrm{t})$ and the applied $\mathrm{AC}$ magnetic field $\left(\mathrm{B}_{\mathrm{AC}}\right), \alpha=(\Delta V) /\left(t \times B_{\mathrm{AC}}\right)$, increases until the ME saturation is reached $\left(\approx 35 \mathrm{mV} \mathrm{cm}^{-1} \mathrm{Oe}^{-1}\right)$ at $\approx 500$ Oe. For higher DC magnetic fields, a decrease in the induced voltage is observed resulting from the saturation of the magnetostriction [47-49].

Since the DC magnetic field at which the cell culture is performed will vary between 0 and $\approx 230$ Oe (arrows of Fig. $1 \mathrm{~b}$ ), the maximum $\alpha$, strain and voltage within the films will be $23 \mathrm{mV} \mathrm{cm}^{-1} \mathrm{Oe}^{-1}, 110 \mathrm{ppm}$ and $0.115 \mathrm{mV}$, respectively. Without the application of the DC field, $\alpha$, strain and voltage values within the films will be 0 . In this way all these parameters will be continually changed from the maximum value to zero during the dynamic cell culture and all the parameters will be kept zero during the static condition.

The strain value was determined from Eqs. (2) and (3) (see experimental methods) using the parameters shown in Table 2.

The influence of the magnetic stimulus on cell proliferation in the different PVDF-TrFE and TD/PVDF-TrFE composite films is represented in Fig. 2. As previously mentioned, cell culture was performed in three modes: Samples A, non-poled PVDF-TrFE samples, with no mechanical or electrical reaction to the magnetic field; samples B, non-poled TD/PVDF-TrFE composites, which produce mechanical variations of the magnetostrictive nanoparticles in response to the magnetic field variation and samples $C$, poled TD/PVDF-TrFE composites, which also produce an electric voltage variation. Further, in order to mimic the human body mechanical stimulation along the day, the dynamic culture was performed with an active time of $16 \mathrm{~h}$ and a non-active time of $8 \mathrm{~h}$.

It was observed that dynamic culture (cell culture under a varying magnetic field) improves cell proliferation on TD/PVDF-TrFE films. No significant differences between the static and dynamic conditions were observed on the negative control (PVDF-TrFE films-A samples), revealing that MC3T3-E1 osteoblast proliferation is not affected by the application of DC magnetic fields on samples without magnetostrictive nanoparticles.

On B samples, an increase of $\approx 20 \%$ in cell number from static to dynamic conditions was detected as a result of the mechanical stimulation of cells, confirming the mechanical sensitivity of osteoblasts reported on previous studies [44,45].

On the other hand, on $C$ samples a higher increase of $\approx 25 \%$ in the number of cells from static to dynamic conditions was observed as a result of the mechanical and electrical stimulation of cells. In this way, together with the mechanical stimulus (up to $110 \mathrm{ppm}$ strain variation), the varying charged surfaces and electrical stimulation (up to $0.115 \mathrm{mV}$ voltage variation) enhance the bone tissue proliferation $[17,18]$.

The differences between the cell numbers detected on the $\mathrm{B}$ and $\mathrm{C}$ scaffolds is related with the piezoelectric coefficient of the later $\left(\mathrm{d}_{33} \approx-6 \mathrm{pCN}^{-1}\right.$-similar to piezoelectric coefficient found in human bones [50]) resultant from the PVDF-TrFE poling. Such a low value of $d_{33}$, as compared with pristine PVDF-TrFE films [39], is due to the large amount ( $40 \%)$ of TD particles $(1 \mu \mathrm{m})$ that prevent a homogeneous poling of the samples as a result of the low resistance Terfenol-D particle percolation path [51].

Cell density on the different substrates was quantified and displayed in Fig. 3.

Fig. 3 shows that higher cell density values are obtained under dynamic conditions on B and C samples, which is consistent with the MTS results. The highest cell density value was detected on $C$ scaffolds under dynamic conditions with an average value of 962 cells $\mathrm{mm}^{2}$, with minimal and maximal densities of 659 and 1455 cells $\mathrm{mm}^{2}$ respectively, whereas in static conditions the average value was 591 cells $\mathrm{mm}^{2}$. Regarding B scaffolds, it was observed an average value of 504 cells $\mathrm{mm}^{2}$ in static conditions and 817 cells $\mathrm{mm}^{2}$ in dynamic conditions. Finally, concerning A scaffolds, similar average values $\left(\approx 550\right.$ cells $\mathrm{mm}^{2}$ ) were observed for both conditions (static and dynamic). The lower the difference between the highest and the smallest cell numbers for the same scaffold, the more uniform will be the cell distribution in the biomaterial. In this way, B and C scaffolds colonized under dynamic conditions show preferential areas of cell growth as a result of the local interactions between cells and mechanical/electrical stimulus (located preferentially close to the magnetic particles).

Finally, cell morphology, number and density were analyzed by fluorescence microscopy (Fig. 4).

No significant differences on cell morphology were found between the different films. Nevertheless, results from Figs. 1 and 2 are confirmed: no differences are detected on cell behavior between static and dynamic conditions on the A scaffolds; a high number of cells was detected under dynamic conditions for $B$ and $C$ scaffolds, the highest number of cells observed on the later. It was also observed the existence of preferential areas of cell growth on scaffolds with TD (B and C).

Table 2

$\alpha, \mathrm{mv}, \mathrm{d}_{33}, \varepsilon, E_{\mathrm{Y}}, \mathrm{l}, w$, and $t$ values used to determine $\lambda$ and $d \mathrm{~S} / \mathrm{dh}$.

\begin{tabular}{|c|c|c|c|c|c|c|c|}
\hline$\alpha \mathrm{mV} \mathrm{cm}^{-1} \mathrm{Oe}^{-1}$ & $\mathrm{mv}$ & $\left|\mathrm{d}_{33}\right| \mathrm{pCN}^{-1}$ & $\varepsilon$ & $E_{Y} \mathrm{GPa}$ & $w \times l \times t(\mathrm{~mm} \times \mathrm{mm} \times \mu \mathrm{m})$ & $\mathrm{ds} / \mathrm{dH} \times 10^{-9}$ & $\lambda \mathrm{ppm}$ \\
\hline 23 & 0.2 & 6 & 25 & 1.4 & $10 \times 4 \times 50$ & 6 & 110 \\
\hline
\end{tabular}




\section{Discussion}

This reports shows the suitability of the ME effect for novel tissue engineering strategies and, in particular, for bone tissue engineering. The prepared films allow cell culture under magnetic, mechanical and electrical stimuli (Fig. 5), triggered by an external magnetic field, being the highest increase of $\approx 25 \%$ in cells number observed as a result of the mechanical and electrical stimulation of cells. Simultaneously with the mechanical stimulus (up to $110 \mathrm{ppm}$ strain) - Fig. 5, mechanical -, the varying charged surfaces and electrical stimulations (up to $0.115 \mathrm{mV}$ ) - Fig. 5, mechano-electric, enhanced the MC3T3-E1 pre-osteoblast cells proliferation.

Whereas, magnetic field does not seem to influence cell growth [52], mechanical cues act in diverse cellular processes ranging from proliferation to transcription and organogenesis due to changes in gene expression, second messenger signaling (such as intracellular $\mathrm{Ca}^{2+}$ ), focal adhesion complexes and internal remodeling of the cytoarchitecture $[53,42]$. Further, mechano-electrical stimulation affects cell adhesion, orientation and migration and influences regulation of morphological and phenotypic processes involved in the cell proliferation and differentiation [54,55], resulting in a change in the cell membrane voltage, GAG synthesis, expression of extracellular genes, reduction of inflammatory mediators, among others [42]. Such effects that can be further investigated and tailored with the help of this innovative platform for tissue engineering.

\section{Conclusions}

This work demonstrates the suitability of the magnetoelectric effect for tissue engineering applications. Magnetoelectric Terfenol-D/poly(vinylidene fluoride-co-trifluoroethylene) composites, acting as cell supports, were used to provide mechanical and electrical stimuli to MC3T3-E1 pre-osteoblast cells, the stimuli being remotely triggered by the application of a varying magnetic field. Cell proliferation was enhanced up to $\approx 25 \%$ when cells are cultured under mechanical and electrical stimulation. Thus, it is shown that magnetoelectric cell stimulation is a suitable approach for novel tissue engineering strategies, allowing magnetic, mechanical and electrical stimuli of cells both in vivo and in vitro.

\section{Acknowledgements}

This work is funded by FEDER funds through the "Programa Operacional Fatores de Competitividade-COMPETE" and by national funds arranged by FCT-Fundação para a Ciência e a Tecnologia, project reference PEST-C/FIS/UI607/2014. C.R., V.C. and P.M. thank the FCT for the SFRH/BPD/90870/2012, SFRH/BPD/96227/2013 and SFRH/BPD/97739/2013 grants, respectively. The authors thank financial support from the Basque Government Industry Department under the ELKARTEK Program. S.L.M. thanks the Diputación de Bizkaia for financial support under the Bizkaia Talent program.

\section{References}

[1] S. Chung, M.W. King, Design concepts and strategies for tissue engineering scaffolds, Biotechnol. Appl. Biochem. 58 (2011) 423-438.

[2] M.P. Lutolf, J.A. Hubbell, Synthetic biomaterials as instructive extracellular microenvironments for morphogenesis in tissue engineering, Nat. Biotechnol. 23 (2005) 47-55.

[3] T.A. Einhorn, L.C. Gerstenfeld, Fracture healing: mechanisms and interventions, Nat. Rev. Rheumatol. 11 (2015) 45-54.

[4] E. Quinlan, A. López-Noriega, E. Thompson, H.M. Kelly, S.A. Cryan, F.J. O’Brien, Development of collagen-hydroxyapatite scaffolds incorporating PLGA and alginate microparticles for the controlled delivery of rhBMP-2 for bone tissue engineering, J. Control. Release 198 (2015) 71-79.

[5] P.S. Malchesky, Artificial organs 2014: a year in review, Artif. Organs 39 (2015) 260-287

[6] Y. Ikada, Challenges in tissue engineering, J. R. Soc. Interface 3 (2006) 589-601
[7] L. Bacakova, E. Filova, M. Parizek, T. Ruml, V. Svorcik, Modulation of cell adhesion, proliferation and differentiation on materials designed for body implants, Biotechnol. Adv. 29 (2011) 739-767.

[8] F.J. O'Brien, Biomaterials \& scaffolds for tissue engineering, Mater. Today 14 (2011) 88-95.

[9] A.R. Costa-Pinto, R.L. Reis, N.M. Neves, Scaffolds based bone tissue engineering: the role of chitosan, Tissue Eng. B 17 (2011) 331-347.

[10] S. Pina, J.M. Oliveira, R.L. Reis, Natural-based nanocomposites for bone tissue engineering and regenerative medicine: a review, Adv. Mater. 27 (2015) 1143-1169.

[11] J. Venkatesan, I. Bhatnagar, P. Manivasagan, K.-H. Kang, S.-K. Kim, Alginate composites for bone tissue engineering: a review, Int. J. Biol. Macromol. 72 (2015) 269-281.

[12] S.J. Simske, R.A. Ayers, T.A. Bateman, Porous materials for bone engineering, Mater. Sci. Forum 250 (1997) 151-182.

[13] M.E. Gomes, A.S. Ribeiro, P.B. Malafaya, R.L. Reis, A.M. Cunha, A new approach based on injection moulding to produce biodegradable starch-based polymeric scaffolds: morphology, mechanical and degradation behaviour, Biomaterials 22 (2001) 883-889.

[14] Q.P. Pham, U. Sharma, A.G. Mikos, Electrospinning of polymeric nanofibers for tissue engineering applications: a review, Tissue Eng. 12 (2006) 1197-1211.

[15] J.F. Mano, C.M. Vaz, S.C. Mendes, R.L. Reis, A.M. Cunha, Dynamic mechanical properties of hydroxyapatite-reinforced and porous starch-based degradable biomaterials, J. Mater. Sci. Mater. Med. 10 (1999) 857-862.

[16] E. Fukada, I. Yasuda, On the piezoelectric effect of bone, J. Phys. Soc. Jpn. 12 (1957) 1158-1162

[17] C. Ribeiro, J. Pärssinen, V. Sencadas, V. Correia, S. Miettinen, V.P. Hytönen, S. Lanceros-Méndez, Dynamic piezoelectric stimulation enhances osteogenic differentiation of human adipose stem cells, J. Biomed. Mater. Res. A 103 (2015) 2172-2175

[18] C. Ribeiro, S. Moreira, V. Correia, V. Sencadas, J.G. Rocha, F.M. Gama, J.L. Gómez Ribelles, S. Lanceros-Méndez, Enhanced proliferation of pre-osteoblastic cells by dynamic piezoelectric stimulation, RSC Adv. 2 (2012) 11504-11509.

[19] M.T. Rodrigues, M.E. Gomes, J.F. Mano, R.L. Reis, $\beta$-PVDF membranes induce cellular proliferation and differentiation in static and dynamic conditions, Mater. Sci. Forum 587-588 (2008) 72-76

[20] J. Parssinen, H. Hammarén, R. Rahikainen, V. Sencadas, C. Ribeiro, S. Vanhatupa, S. Miettinen, S. Lanceros-Méndez, V.P. Hytönen, Enhancement of adhesion and promotion of osteogenic differentiation of human adipose stem cells by poled electroactive poly(vinylidene fluoride), J. Biomed. Mater. Res. A 103 (2015) 919-928.

[21] M. Mehta, K. Schmidt-Bleek, G.N. Duda, D.J. Mooney, Biomaterial delivery of morphogens to mimic the natural healing cascade in bone, Adv. Drug Deliv. Rev. 64 (2012) 1257-1276.

[22] J. Dobson, Remote control of cellular behaviour with magnetic nanoparticles, Nat. Nanotechnol. 3 (2008) 139-143.

[23] R. Guduru, S. Khizroev, Magnetic field-controlled release of Paclitaxel drug from functionalized magnetoelectric nanoparticles, Part. Part. Syst. Char. 31 (2014) 605-611.

[24] D.M. Evans, A. Schilling, A. Kumar, D. Sanchez, N. Ortega, M. Arredondo, R.S. Katiyar, J.M. Gregg, J.F. Scott, Magnetic switching of ferroelectric domains at room temperature in multiferroic PZTFT, Nat. Commun. 4 (2013) 1534.

[25] R. Goncalves, P. Martins, D.M. Correia, V. Sencadas, J.L. Vilas, L.M. Leon, G. Botelho, S. Lanceros-Mendez, Development of magnetoelectric $\mathrm{CoFe}_{2} \mathrm{O}_{4} /$ poly(vinylidene fluoride) microspheres, RSC Adv. 5 (2015) 35852-35857.

[26] Y. Li, Z. Wang, J. Yao, T. Yang, Z. Wang, J.M. Hu, C. Chen, R. Sun, Z. Tian, J. Li, L.Q. Chen, D. Viehland, Magnetoelectric quasi- $(0-3)$ nanocomposite heterostructuresetoelectric quasi-(0-3) nanocomposite heterostructures, Nat. Commun. 6 (2015) 6680.

[27] P. Martins, S. Lanceros-Méndez, Polymer-based magnetoelectric materials, Adv. Funct. Mater. 23 (2013) 3371-3385.

[28] A.S. Mistry, A.G. Mikos, Tissue engineering strategies for bone regeneration, Adv. Biochem. Eng. Biotechnol. 95 (2005) 1-22.

[29] P. Martins, R. Gonçalves, S. Lanceros-Mendez, A. Lasheras, J. Gutiérrez, J.M. Barandiarán, Effect of filler dispersion and dispersion method on the piezoelectric and magnetoelectric response of $\mathrm{CoFe}_{2} \mathrm{O}_{4} / \mathrm{P}(\mathrm{VDF}-\mathrm{TrFE})$ nanocomposites, Appl. Surf. Sci. 313 (2014) 215-219.

[30] J. Jin, S.G. Lu, C. Chanthad, Q. Zhang, M.A. Haque, Q. Wang, Multiferroic polymer composites with greatly enhanced magnetoelectric effect under a low magnetic bias, Adv. Mater. 23 (2011) 3853-3858.

[31] M. Silva, S. Reis, C.S. Lehmann, P. Martins, S. Lanceros-Mendez, A. Lasheras, J. Gutiérrez, J.M. Barandiarán, Optimization of the magnetoelectric response of poly(vinylidene fluoride)/epoxy/vitrovac laminatesmization of the magnetoelectric response of poly(vinylidene fluoride)/epoxy/vitrovac laminates, ACS Appl. Mater. Interfaces 5 (2013) 10912-10919.

[32] R. Gonçalves, P. Martins, X. Moya, M. Ghidini, V. Sencadas, G. Botelho, N.D. Mathur, S. Lanceros-Mendez, Magnetoelectric $\mathrm{CoFe}_{2} \mathrm{O}_{4} /$ polyvinylidene fluoride electrospun nanofibres, Nanoscale 7 (2015) 8058-8061.

[33] H.Y. Xu, N. Gu, Magnetic responsive scaffolds and magnetic fields in bone repair and regeneration, Front. Mater. Sci. 8 (2014) 20-31.

[34] S. Gil, J.F. Mano, Magnetic composite biomaterials for tissue engineering, Biomater. Sci. 2 (2014) 812-818.

[35] G.S. Baht, D. Silkstone, L. Vi, P. Nadesan, Y. Amani, H. Whetstone, Q. Wei, B.A. Alman, Exposure to a youthful circulaton rejuvenates bone repair through modulation of $\beta$-catenin, Nat. Commun. 6 (2015) 7131. 
[36] S. Dong, J. Cheng, J.F. Li, D. Viehland, Enhanced magnetoelectric effects in laminate composites of Terfenol-D/Pb(ZrTi) $\mathrm{O}_{3}$ under resonant drive, Appl. Phys. Lett. 83 (2003) 4812-4814.

[37] P. Pouponneau, L. Yahia, Y. Merhi, L.M. Epure, S. Martel, Biocompatibility of candidate materials for the realization of medical microdevices, Annu. Int Conf. Proc. IEEE Eng. Med. Biol. Soc. 1 (2006) 2362-2365.

[38] C. Ribeiro, D.M. Correia, S. Ribeiro, V. Sencadas, G. Botelho, S Lanceros-Méndez, Piezoelectric poly(vinylidene fluoride) microstructure and poling state in active tissue engineering, Eng. Life Sci. 15 (2015) 351-356.

[39] P. Martins, A.C. Lopes, S. Lanceros-Mendez, Electroactive phases of poly(vinylidene fluoride): determination, processing and applications, Prog. Polym. Sci. 39 (2014) 683-706.

[40] P. Martins, A. Lasheras, J. Gutierrez, J.M. Barandiaran, I. Orue, S. Lanceros-Mendez, Optimizing piezoelectric and magnetoelectric responses on $\mathrm{CoFe}_{2} \mathrm{O}_{4} / \mathrm{P}($ VDF-TrFE) nanocomposites, J. Phys. D Appl. Phys. 44 (2011) 495303.

[41] P. Martins, M. Silva, S. lanceros-mendez, Determination of the magnetostrictive response of nanoparticles via magnetoelectric measurements, Nanoscale 21 (2015) 9457-9461.

[42] X. Yuan, D.E. Arkonac, P.H.G. Chao, G. Vunjak-Novakovic, Electrical stimulation enhances cell migration and integrative repair in the meniscus, Sci. Rep. 4 (2015) 3674.

[43] K. Spiegel, R. Leproult, E. Van Cauter, Impact of sleep debt on metabolic and endocrine function, Lancet (1999) 1435-1439.

[44] S.H. Cartmell, A. Keramane, G.R. Kirkham, S.B. Verschueren, J.L. Magnay, A.J. El Haj, J. Dobson, Use of magnetic particles to apply mechanical forces for bone tissue engineering purposes, J. Phys. Conf. Ser. 17 (2005) 77-80.

[45] J. Meng, B. Xiao, Y. Zhang, J. Liu, H. Xue, J. Lei, H. Kong, Y. Huang, Z. Jin, N. Gu, H. Xu, Super-paramagnetic responsive nanofibrous scaffolds under static magnetic field enhance osteogenesis for bone repair in vivo, Sci Reports 3 (2013) 2655
[46] C. Ribeiro, J.A. Panadero, V. Sencadas, S. Lanceros-Méndez, M.N. Tamaño, D. Moratal, M. Salmerón-Sánchez, J.L. Gómez Ribelles, Fibronectin adsorption and cell response on electroactive poly(vinylidene fluoride) films, Biomed. Mater. 7 (2012) 035004

[47] X.W. Dong, B. Wang, K.F. Wang, J.G. Wan, J.M. Liu, Ultra-sensitive detection of magnetic field and its direction using bilayer PVDF/Metglas laminate, Sens. Actuator A-Phys. 153 (2009) 64-68.

[48] Y.S. Koo, K.M. Song, N. Hur, J.H. Jung, T.H. Jang, H.J. Lee, T.Y. Koo, Y.H. Jeong, J.H. Cho, Y.H. Jo, Strain-induced magnetoelectric coupling in $\mathrm{BaTiO} / \mathrm{Fe}_{3} \mathrm{O}_{4}$ core/shell nanoparticles, Appl. Phys. Lett. 94 (2009) 032903

[49] Y.X. Zheng, Q.Q. Cao, C.L. Zhang, H.C. Xuan, L.Y. Wang, D.H. Wang, Y.W. Du, Study of uniaxial magnetism and enhanced magnetostriction in magnetic-annealed polycrystalline $\mathrm{CoFe}_{2} \mathrm{O}_{4}$, J. Appl. Phys. 110 (2011) 043908

[50] C. Halperin, S. Mutchnik, A. Agronin, M. Molotskii, P. Urenski, M. Salai, G. Rosenman, Piezoelectric effect in human bones studied in nanometer scale, Nano Lett. 4 (2004) 1253-1256.

[51] Y. Zeng, G. Bao, J. Yi, G. Zhang, S. Jiang, The influence of inducing magnetic field on the magnetoelectric effect of particulate magnetoelectric composites, J. Alloys Compd. 630 (2015) 183-188.

[52] J. Miyakoshi, The review of cellular effects of a static magnetic field, Sci. Technol. Adv. Mater. 7 (2006) 305-307.

[53] N.V. Bukoreshtliev, K. Haase, A.E. Pelling, Mechanical cues in cellular signalling and communication, Cell Tissue Res. 352 (2013) 77-94.

[54] H.S. Dhowre, S. Rajput, N.A. Russell, M. Zelzer, Responsive cell-material interfaces, Nanomedicine 10 (2015) 849-871

[55] M.L. Hernández-Bule, C.L. Paíno, M.A. Trillo, A. Úbeda, Electric stimulation at $448 \mathrm{kHz}$ promotes proliferation of human mesenchymal stem cells, Cell Phys. Biochem. 34 (2014) 1741-1755. 